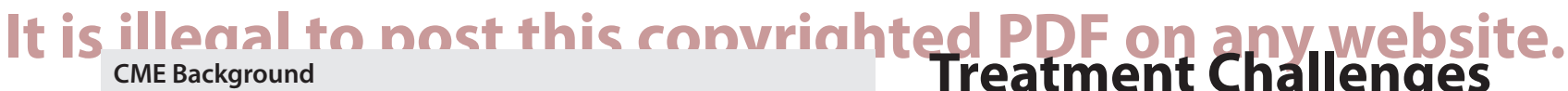 \\ Articles are selected for credit designation based on an assessment of the educational needs of CME participants, with the purpose of providing readers with a curriculum of CME articles on a variety of topics throughout each volume. Activities are planned using a process that links identified needs with desired results. \\ To obtain credit, read the article, correctly answer the questions in \\ Treatment Challenges and the Hope of Emerging Therapies in Early-Stage Alzheimer Disease
} the Posttest, and complete the Evaluation.

This ACADEMIC HIGHLIGHTS section of The Journal of Clinical Psychiatry presents the highlights of the teleconference series "Diagnosis of Early-Stage Alzheimer Disease and How Emerging Treatments May Address Unmet Needs," which was held in August and October 2020. This report was prepared and independently developed by the CME Institute of Physicians Postgraduate Press, Inc., and was supported by an educational grant from Biogen.

The teleconference was chaired by Anna D. Burke, MD, Barrow Neurological Institute, Phoenix, Arizona. The faculty member was Liana Apostolova, MD, MSc, Indiana University School of Medicine, Indianapolis.

\section{CME Objective}

After studying this article, you should be able to:

- Provide evidence-based treatment for patients with earlystage Alzheimer disease

\section{Accreditation Statement}

The CME Institute of Physicians Postgraduate Press, Inc., is accredited by the Accreditation Council for Continuing Medical Education to provide continuing medical education for physicians.

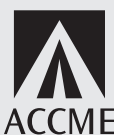
ACCRME

Release, Expiration, and Review Dates

This educational activity was published in June 2021 and is eligible for AMA PRA Category 1 Credit $^{\text {TM }}$ through August 31, 2023. The latest review of this material was June 2021.

\section{Financial Disclosure}

All individuals in a position to influence the content of this activity were asked to complete a statement regarding all relevant personal financial relationships between themselves or their spouse/partner and any commercial interest. The CME Institute has resolved any conflicts of interest that were identified. In the past year, Marlene P. Freeman, MD, Editor in Chief, has received research funding from JayMac and Sage; has been a member of the advisory boards for Otsuka, Alkermes, and Sunovion; and has been a member of the Independent Data Safety and Monitoring Committee for Janssen. No member of the CME Institute staff reported any relevant personal financial relationships. Faculty financial disclosure appears on the next page.

J Clin Psychiatry 2021;82(4):BG20044AH4C

To cite: Burke AD, Apostolova L. Treatment challenges and the hope of emerging therapies in early-stage Alzheimer disease. J Clin Psychiatry. 2021;82(4):BG20044AH4C

To share: https://doi.org/10.4088/JCP.BG20044AH4C

(.) Copyright 2021 Physicians Postgraduate Press, Inc.

\author{
Anna D. Burke, MD, and Liana Apostolova, MD, MSc
}

A lzheimer's disease (AD), the most common cause of dementia, is a degenerative brain disease with no cure. ${ }^{1}$ Symptoms of dementia include problems with memory, language, and other cognitive and functional abilities that hinder individuals from managing activities of daily living.

In this Academic Highlights, Drs Burke and Apostolova will address best practices for identifying patients with early-stage $\mathrm{AD}$, discussing treatment goals and challenges with patients who have $\mathrm{AD}$ and their care partners, employing medications approved by the US Food and Drug Administration (FDA) to slow symptom progression, and staying informed about emerging therapies that offer new hope for disease modification.

\section{PATHOPHYSIOLOGY AND DIAGNOSIS}

In her presentation, Dr Apostolova reported that $\mathrm{AD}$ accounts for $60 \%-80 \%$ of dementia cases; vascular dementia is the second most common, with $5 \%-10 \%$ of cases; and Lewy body disease is the third most common, with approximately $5 \%$ of cases. ${ }^{2}$ In the United States alone, an estimated 5.8 million people are living with AD: 1 in 10 Americans aged 65 years and older and 1 in 3 Americans aged 85 years and older.

Pathophysiology. The pathological hallmark of AD is the accumulation of amyloid plaques in the brain. ${ }^{3}$ Dr Apostolova described how the degradation of the amyloid precursor protein (APP) by $\beta$-secretase and then again by $\gamma$-secretase forms the amyloid- $\beta$ (A $\beta)$ protein, ${ }^{3}$ which misfolds and then polymerizes into oligomers, protofibrils, and, ultimately amyloid fibrils. ${ }^{4}$ The toxic oligomers and protofibrils accelerate the plaque buildup. The synaptic loss and neuronal death that follow result from the toxic effects of $A \beta$ and some other misfolded proteins such as tau. Cognitive decline and functional decline then occur. ${ }^{4}$

Diagnosis. Dr Apostolova stated that, although some cognitive decline is associated with normal aging, the decline in adults with $\mathrm{AD}$ is more abrupt and less subtle. ${ }^{2,5}$ One example is the difference between stopping occasionally to think through directions while driving versus having a tendency to get lost in familiar areas.

The Diagnostic and Statistical Manual of Mental Disorders, Fifth Edition (DSM-5) ${ }^{6}$ describes mild and 


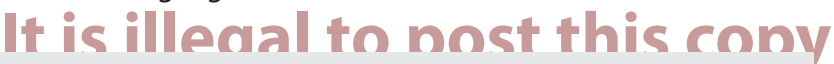 Credit Designation \\ The CME Institute of Physicians Postgraduate Press, Inc., designates this journal-based CME activity for a maximum of 1 AMA PRA Category 1 Credit $^{\mathrm{TM}}$. Physicians should claim only the credit commensurate with the extent of their participation in the activity. \\ Note: The American Nurses Credentialing Center (ANCC) and the American Academy of Physician Assistants (AAPA) accept certificates of participation for educational activities certified for AMA PRA Category 1 Credit $^{\mathrm{TM}}$ from organizations accredited by the ACCME. \\ (5) diagnostic confirmation through use of $A D$-specific biomarkers. ${ }^{6,9-11}$ Dr Burke shared that, in her clinical experience, neuropsychologic testing offers not only information that supports diagnosis but also a description of a patient's cognitive strengths and weaknesses (eg, short-term memory, long-term memory, how they plan and organize information, how their brain processes what their eyes are seeing). Knowing this pattern is valuable to clinicians in formulating a treatment plan tailored to the patient's unique needs, she added.}

\section{Financial Disclosure}

Dr Burke has no personal affiliations or financial relationships with any commercial interest to disclose relative to the activity. Dr Apostolova has received grant/research support from AVID, Life Molecular Imaging, and Roche; is a consultant and/or member of the speakers/advisory board for Biogen, Two Labs, and Lilly; is a member of the Data Safety and Monitoring Board for IQVIA; and her husband is a stock shareholder of Semiring.

\section{Review Process}

The faculty member(s) agreed to provide a balanced and evidence-based presentation and discussed the topic(s) and CME objective(s) during the planning sessions. The faculty's submitted content was validated by CME Institute staff, and the activity was evaluated for accuracy, use of evidence, and fair balance by the Chair and a peer reviewer who is without conflict of interest.

The opinions expressed herein are those of the faculty and do not necessarily reflect the opinions of the CME provider and publisher or the commercial supporter.

major neurocognitive impairment. Major neurocognitive impairment (dementia) requires objective cognitive decline that is severe enough to interfere with daily living. Mild neurocognitive impairment does not deprive an individual of the ability to lead an independent lifestyle and perform complex daily activities, but more effort or compensatory strategies may be needed. Dr Apostolova pointed out that, although an amnestic presentation is typical, ${ }^{6}$ the DSM-5 criteria do not require the presence of memory impairment.

Another set of diagnostic criteria was developed by the National Institute on Aging (NIA) and the Alzheimer's Association (AA). ${ }^{5}$ The NIA-AA diagnostic criteria describe mild cognitive impairment $(\mathrm{MCI})^{7}$ and probable AD. ${ }^{8}$ These criteria for dementia also do not require memory impairment to be present, but they necessitate documentation of impairment in 2 cognitive domains or 1 cognitive and 1 behavioral domain in addition to significant decline in daily functioning.

Dr Apostolova identified components in the diagnostic process for MCI and AD: (1) cognitive screening, (2) laboratory assessments, (3) structural imaging of the brain, (4) full neuropsychologic assessment (if warranted), and

\section{Case Practice Question}

Discussion of the best response can be found at the end of the activity.

Case. Alvin is a 63-year-old man who has developed subtle shortterm memory loss. He has a family history of AD. The results of Alvin's laboratory tests and magnetic resonance imaging of the brain are normal. Neuropsychologic testing reveals a pattern that leads you to suspect $\mathrm{MCl}$. At this time, even if $\mathrm{AD}$ is present, amyloid will not yet be visible if Alvin undergoes amyloid positron emission tomography (PET) imaging.
a. True
b. False

\section{TALKING WITH PATIENTS AND CARE PARTNERS ABOUT EARLY-STAGE AD}

Drs Burke and Apostolova discussed the myriad concerns that patients and care partners express to them in their practices. For example, if individuals have a family history of dementia, they ask if they too will develop it. Dr Apostolova highlighted a study ${ }^{12}$ that reviewed the genetic risk factors for $\mathrm{AD}$ and their role in $\mathrm{AD}$ pathogenesis. Drs Burke and Apostolova emphasized that, unless a person carries the rare autosomal genes that cause familial AD_APP, presenilin 1 (PPSEN1), and presenilin 2 (PPSEN2) - genetic variations are only a risk factor, not a guarantee that the person will develop the condition. ${ }^{12}$ A systematic review and meta-analysis ${ }^{13}$ described risk factors with strong evidence as those related to education, cognitive activity, high body mass index in late life, hyperhomocysteinemia, depression, stress, diabetes, head trauma, hypertension in midlife, and orthostatic hypotension. Factors with weaker evidence include obesity in midlife, weight loss in late life, physical exercise, smoking, sleep, cerebrovascular disease, frailty, atrial fibrillation, and vitamin C. ${ }^{13}$ Drs Burke and Apostolova recommend a Mediterranean diet based on evidence from clinical trials. ${ }^{14-16}$

\section{Treatment}

Dr Burke stated that there are currently no FDAapproved therapies for mild neurocognitive disorder as no treatment trial to date has convincingly demonstrated a significant effect on cognition or symptom progression. ${ }^{17}$ Whether the problem lies with the evaluated compounds 


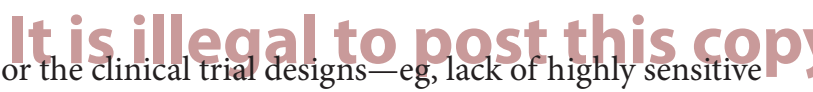
assessments and reliable outcomes tools with the power to detect change and treatment benefit in mildly impaired subjects-remains unclear.

The current FDA-approved medications for the treatment of AD slow symptom progression but do not arrest the disease process. ${ }^{18}$ The limited arsenal of medications to treat $\mathrm{AD}$ symptoms comprises the acetylcholinesterase inhibitors donepezil, rivastigmine, and galantamine and the NMDA receptor antagonist memantine. These "cognitive enhancers" also show benefit for behavioral symptoms, such as agitation and apathy. Although better treatment is needed, ${ }^{19}$ these medications have efficacy and seem more beneficial to patients when started as early as possible; guidelines ${ }^{18,20}$ recommend initiation at diagnosis. When discussing treatment with patients and care partners, clinicians need to be sure to explain what to expect from treatment, including both therapeutic effects and adverse effects.

\section{Family Perspectives}

Here, care partners express confusion and frustration about the level of information they received on medication:

"My mom was just diagnosed... So far, the doctor advised that she should be eating coconut oil and should come back in 4 months. Does that seem right? I feel like we need to do something now... maybe medication? I guess I have to be patient."21

"My mother was just diagnosed with moderate Alzheimers. Trying to navigate where to even begin. Medication? Her doctor rattled off several and asked us which one we want to start her on. How do we know which one to choose?"22

"She started with one kind of medication and she was having really bad nightmares, some real troubling sleep disturbances. So, she just quit taking it but didn't tell anyone she quit taking it. And then she started taking it again, then she quit taking it, but nobody had said this [side effect] could happen until she came in and said I quit taking this because of what was happening... and the doctor was like, 'Oh yeah, those things could happen."'123

\section{CAN EMERGING THERAPIES RESOLVE UNMET NEEDS WITH CURRENT TREATMENT IN EARLY-STAGE AD?}

Dr Burke identified the goals of AD treatment as improving the symptoms and slowing or even arresting the disease progression. While no FDA-approved disease-modifying medications for $\mathrm{AD}$ exist to address the neuronal damage, clinical trials are in progress on drugs with a variety of mechanisms such as neuronal protection, protein synthesis or aggregation inhibition, and immunologic priming with antibodies, vaccines, and secretase inhibition. ${ }^{24}$

Dr Burke explained that disease-modifying therapies for $\mathrm{AD}$ currently in the research stages may modulate the disease process through a variety of mechanisms of action. One of the most broad areas of research for emerging therapies for AD has been the $\beta$ amyloid cascade hypothesis. ${ }^{25}$ Technologies such as PET imaging can identify biomarkers of brain $\beta$-amyloidosis in individuals who are still cognitively normal. ${ }^{26} \mathrm{Dr}$ Burke said that understanding how early such changes occur and identifying them at the preclinical and mild cognitive impairment stages of $\mathrm{AD}$ allows clinicians the opportunity to modulate the disease before significant functional impairments occur. She discussed 2 medications, aducanumab and gantenerumab, that are injectable antibodies showing promise in reducing brain amyloid. ${ }^{27,28}$

In conclusion, Drs Burke and Apostolova emphasized early intervention in treating patients with $\mathrm{AD}$. To hear more from Drs Burke and Apostolova, see their 3 webcast activities in this CME series.

\section{Clinical Points}

- The diagnostic process for $\mathrm{MCl}$ and $\mathrm{AD}$ includes cognitive screening, laboratory assessments, structural imaging evaluation of the brain, full neuropsychologic assessment (if warranted), and biomarker confirmation.

- Use neuropsychologic testing to identify an individual's cognitive strengths and weaknesses and what type of dementia the results are consistent with.

- Upon diagnosis, start available medications that slow the progression of symptoms associated with $A D$, and stay informed about emerging therapies that may modulate the disease process.

\section{Discussion of Case Practice Question}

\section{Preferred response is $\mathrm{b}$. False}

Amyloid buildup occurs 10 to 20 years before emergence of clinical symptoms. ${ }^{29}$ Hence, if Alvin is displaying short-term memory loss due to $A D$, amyloid should be visible on an amyloid PET scan even in the $\mathrm{MCl}$ stages. ${ }^{11}$

Published online: June 15, 2021.

Disclosure of off-label usage: Dr Burke has determined that, to the best of her knowledge, aducanumab and gantenerumab are not approved by the US Food and Drug Administration for the treatment of Alzheimer disease.

\section{REFERENCES}

1. Alzheimer's Association. 2019 Alzheimer's disease facts and figures. Alzheimers Dement. 2019;15(3):321-387.

2. Alzheimer's Association. 2020 Alzheimer's disease facts and figures. Alzheimers Dement. 2020;16(3):391-460.

3. van Es MA, van den Berg LH. Alzheimer's disease beyond APOE. Nat Genet. 2009;41(10):1047-1048.

4. Huang L, Su X, Federoff HJ. Single-chain fragment variable passive immunotherapies for neurodegenerative diseases. Int J Mol Sci. 2013;14(9):19109-19127.

5. Sperling RA, Aisen PS, Beckett LA, et al. Toward defining the preclinical stages of Alzheimer's disease: recommendations from the National Institute on Aging-Alzheimer's Association workgroups on diagnostic guidelines for Alzheimer's disease. Alzheimers Dement. 2011;7(3):280-292.

6. American Psychiatric Association. Diagnostic and Statistical Manual for Mental Disorders. Fifth Edition. Washington, DC: American Psychiatric Association; 2013.

7. Albert MS, DeKosky ST, Dickson D, et al. The diagnosis of mild cognitive impairment due to Alzheimer's disease: recommendations from the 
National Institute on Aging-Alzheimer's Association Workgroups on Diagnostic Guidelines for Alzheimer's Disease. Alzheimers Dement. 2011;7(3):270-279.

8. McKhann GM, Knopman DS, Chertkow H, et al. The diagnosis of dementia due to Alzheimer's disease: recommendations from the National Institute on Aging-Alzheimer's Association Workgroups on Diagnostic Guidelines for Alzheimer's Disease. Alzheimers Dement. 2011;7(3):263-269.

9. Falk N, Cole A, Meredith TJ. Evaluation of suspected dementia. Am Fam Physician. 2018;97(6):398-405.

10. Apostolova LG. Alzheimer disease. Continuum (Minneap Minn). 2016;22(2 dementia):419-434.

11. Suppiah S, Didier M-A, Vinjamuri S. The who, when, why, and how of PET amyloid imaging in management of Alzheimer's disease-review of literature and interesting images. Diagnostics (Basel). 2019;9(2):65.

12. Karch CM, Goate AM. Alzheimer's disease risk genes and mechanisms of disease pathogenesis. Biol Psychiatry. 2015;77(1):43-51.

13. Yu J-T, Xu W, Tan C-C, et al. Evidence-based prevention of Alzheimer's disease: systematic review and meta-analysis of 243 observational prospective studies and 153 randomised controlled trials. J Neurol Neurosurg Psychiatry. 2020;91(11):1201-1209.

14. Baker L, Kivipelto M, Espeland M, et al. POINTER Study. Alzheimer's Association. Published 2021. Accessed March 24, 2021. https://alz.org/ us-pointer/overview.asp

15. Kivipelto M, Mangialasche F, Snyder HM, et al. World-Wide FINGERS Network: a global approach to risk reduction and prevention of dementia. Alzheimers Dement. 2020;16(7):1078-1094.

16. Rosenberg A, Mangialasche F, Ngandu T, et al. Multidomain interventions to prevent cognitive impairment, Alzheimer's disease, and dementia: from FINGER to World-Wide FINGERS. J Prev Alzheimers Dis. 2020;7(1):29-36.

17. Anderson ND. State of the science on mild cognitive impairment (MCl). CNS Spectr. 2019;24(1):78-87.

18. Grossberg GT, Tong G, Burke AD, et al. Present algorithms and future treatments for Alzheimer's disease. J Alzheimers Dis. 2019;67(4):1157-1171.
19. Cummings' New approaches to symptomatic treatments for $\mathrm{S}$ Alzheimer's disease. Mol Neurodegener. 2021;16(1):2.

20. Cummings JL, Isaacson RS, Schmitt FA, et al. A practical algorithm for managing Alzheimer's disease: what, when, and why? Ann Clin Transl Neurol. 2015;2(3):307-323.

21. New diagnosis: Alzheimer's Association message boards. alz connected. Published November 26, 2015. Accessed May 11, 2020. https://www. alzconnected.org/discussion.aspx?g=posts\&t=2147522384

22. New diagnosis, looking for input: Alzheimer's Association message boards. alz connected. Published August 15, 2017. Accessed May 11, 2020. https://www.alzconnected.org/discussion.aspx?g=posts\&t=2147535923

23. Zubatsky M, Aragon-Prada M, Muse F, et al. Navigating without a roadmap: challenges of early Alzheimer's caregivers with their health care team. Glob Qual Nurs Res. 2016;3:2333393616673465.

24. Cummings J, Lee $G$, Ritter $A$, et al. Alzheimer's disease drug development pipeline: 2020. Alzheimers Dement (N Y). 2020;6(1):e12050.

25. Mullard A. Alzheimer amyloid hypothesis lives on. Nat Rev Drug Discov. 2016;16(1):3-5

26. Jack CR Jr, Knopman DS, Jagust WJ, et al. Hypothetical model of dynamic biomarkers of the Alzheimer's pathological cascade. Lancet Neurol. 2010;9(1):119-128.

27. Tolar M, Abushakra S, Hey JA, et al. Aducanumab, gantenerumab, BAN2401, and ALZ-801-the first wave of amyloid-targeting drugs for Alzheimer's disease with potential for near term approval. Alzheimers Res Ther. 2020;12(1):95.

28. Lozupone M, Solfrizzi V, D'Urso F, et al. Anti-amyloid- $\beta$ protein agents for the treatment of Alzheimer's disease: an update on emerging drugs. Expert Opin Emerg Drugs. 2020;25(3):319-335.

29. Dubois $\mathrm{B}, \mathrm{Hampel} \mathrm{H}$, Feldman $\mathrm{HH}$, et al; Proceedings of the Meeting of the International Working Group (IWG) and the American Alzheimer's Association on "The Preclinical State of AD"; July 23, 2015; Washington DC, USA. Preclinical Alzheimer's disease: Definition, natural history, and diagnostic criteria. Alzheimers Dement. 2016;12(3):292-323.

\section{POSTTEST}

To obtain credit, go to PSYCHIATRIST.COM to complete the Posttest and Evaluation.

1. James is a 69-year-old man whom you have diagnosed with mild neurocognitive impairment. He inquires about available treatments for his condition. What is the most appropriate FDA-approved treatment for his condition?
a. Donepezil
b. Galantamine
c. Memantine
d. No treatments are FDA-approved for mild neurocognitive impairment 